\title{
Is there seasonal variation in the prescribing of antidepressants in the community?
}

\author{
KEREN SKEGG, ${ }^{1}$ DCG SKEGG, ${ }^{2}$ AND BW MCDONALD ${ }^{2}$ \\ From the Department of Psychological Medicine, ${ }^{1}$ and the Department of Preventive and Social Medicine, ${ }^{2}$ \\ University of Otago, Dunedin, New Zealand
}

SUMMARY The prescribing of antidepressants by general practitioners might be expected to reflect the incidence of depression in the community. In a two-year study of the prescriptions issued by English general practitioners to a population of 40000 people, the rates of initiating treatment with antidepressants were analysed by month. There was seasonal variation in new antidepressant prescribing for men $(\mathrm{p}<0.025)$, with peaks in early June and early December, but no significant seasonality for women. The bimodal pattern in men was similar to a recently reported seasonal variation in general practice consultations for depression.

There is strong evidence for seasonal variation in suicide $^{12}$ and major affective disorders, ${ }^{3}$ but the evidence for seasonality of milder depression is inconclusive. Eastwood and Stiasny ${ }^{4}$ reported seasonal variation in hospital admissions for neurotic depression, with an autumn peak, but Parker and Walter ${ }^{5}$ found no significant seasonality for this disorder. The bulk of mild affective disorders do not lead to hospital admission and are, therefore, more difficult to study. In his survey of sickness in England and Wales, Stocks ${ }^{6}$ observed the highest prevalence rates of 'nervous complaints' in October and November. McCartney ${ }^{7}$ also reported a higher rate of referral for depressive reactions in the autumn.

Recently, Harris ${ }^{8}$ analysed one year's consultations at five London general practices (with about 33000 patients) and reported a bimodal pattern for depression, with peaks in May-June and NovemberJanuary. A different approach was used by Williams and Dunn, ${ }^{9}$ who studied data on the prescriptions dispensed at retail pharmacies in England. They interpreted the data for antidepressant prescribing as showing a four-monthly cycle (with three cycles a year). One limitation of their study was that repeat prescriptions could not be distinguished from new courses of treatment.

We had an opportunity to study the medicines prescribed over two years for a general practice population of about 40000 people, who were included in a drug monitoring project. ${ }^{10}$ Since it was possible to identify the prescriptions issued to individuals, most repeat prescriptions could be excluded. Our aim was to determine whether there was any seasonality in the initiation of antidepressant treatment in the community.

\section{Methods}

The population included in this study were the people registered with 19 English general practitioners in five group practices. ${ }^{11}$ Basic information about each person-such as sex, date of birth, date of registration with the practice, and date of removal-was obtained from the computer records of the Oxford Community Health Project.

The Prescription Pricing Authority provided photocopies of all prescriptions bearing the stamps of the participating doctors, from 1 March 1974 to 29 February 1976. This method ensured that only prescriptions actually dispensed were recorded. We received the prescriptions written by the practitioners' assistants and locums but not those given by hospital doctors. The method was validated by asking the general practitioners to make carbon copies of all the prescriptions they wrote during sample periods. ${ }^{10}$ Information from each prescription was coded and added to the patient's computer record.

\section{ANALYSIS}

The analysis was confined to the population aged 15 years or older. We counted the number of people who received a prescription for any antidepressant during each month of the study. In order to exclude repeat prescriptions, these counts were restricted to people who had not received any antidepressant during the previous four months. Since prescriptions were 
collected for 24 months, such counts were possible for a total of 20 months. The rates of issuing 'new' prescriptions for antidepressants were calculated, taking account of the number of days in each month.

The approach described by Walter and Elwood ${ }^{12}$ was used to test for seasonal variation in the prescribing of antidepressants. The data were tested for cycles with periods of one year, six months, and four months, respectively.

\section{Results}

The numbers of men and women receiving new prescriptions for antidepressants, together with the eligible populations, are shown in the table. The right-hand columns give the daily rates of new prescribing (per 100000 people). These rates are shown graphically in the figure.

The prescribing rates for men declined significantly over the period of the study, so an adjustment was made for this trend (using linear regression) before we tested for seasonality. There was a statistically significant seasonal variation in antidepressant prescribing for men, with a six-month period $\left(\chi^{2}=7 \cdot 70, \mathrm{df}=2, \mathrm{p}<0.025\right)$. The estimated peaks of prescribing were in early June and early December. The amplitude of the seasonal variation was $27.6 \%$. There was no significant one-year or four-month periodicity.

Although visual inspection of the data for women suggested the possibility of an autumn peak, this was not confirmed by the statistical analysis. There was no

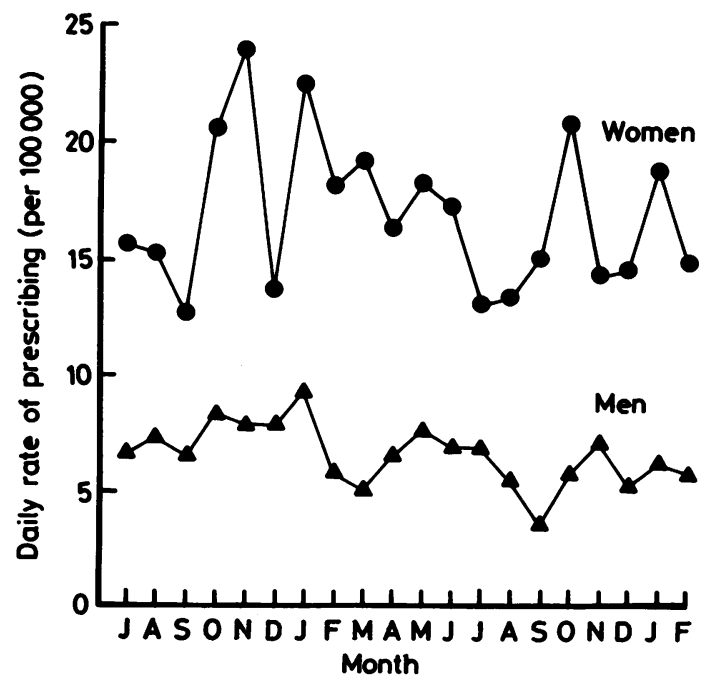

Rates of initiating treatment with antidepressants (per 100000 people per day) over 20 months.
Rates of initiating treatment with antidepressants, by month

\begin{tabular}{|c|c|c|c|c|c|c|}
\hline \multirow[t]{2}{*}{ Month } & \multicolumn{2}{|c|}{$\begin{array}{l}\text { Number receiving } \\
\text { new prescriptions } \\
\text { for antidepressants }\end{array}$} & \multicolumn{2}{|c|}{$\begin{array}{l}\text { Population } \\
\text { at risk* }\end{array}$} & \multicolumn{2}{|c|}{$\begin{array}{l}\text { Daily rate of } \\
\text { prescribing (per } \\
100000 \text { people) }\end{array}$} \\
\hline & Men & Women & Men & Women & Men & Women \\
\hline
\end{tabular}

\begin{tabular}{llrllll}
\hline Year 1) & & & & & & \\
July & 28 & 70 & 13,402 & 14,353 & $6 \cdot 7$ & $15 \cdot 7$ \\
August & 31 & 69 & 13,501 & 14,418 & $7 \cdot 4$ & $15 \cdot 4$ \\
September & 27 & 55 & 13,512 & 14,446 & $6 \cdot 7$ & $12 \cdot 7$ \\
October & 35 & 92 & 13,487 & 14,454 & $8 \cdot 4$ & $20 \cdot 5$ \\
November & 32 & 103 & 13,397 & 14,347 & $8 \cdot 0$ & $23 \cdot 9$ \\
December & 33 & 61 & 13,425 & 14,351 & $7 \cdot 9$ & $13 \cdot 7$ \\
January & 39 & 100 & 13,389 & 14,352 & $9 \cdot 4$ & $22 \cdot 5$ \\
February & 22 & 74 & 13,465 & 14,543 & $5 \cdot 8$ & $18 \cdot 2$ \\
March & 22 & 88 & 13,622 & 14,738 & $5 \cdot 2$ & $19 \cdot 3$ \\
April & 27 & 73 & 13,726 & 14,846 & $6 \cdot 6$ & $16 \cdot 4$ \\
May & 33 & 85 & 13,797 & 14,930 & $7 \cdot 7$ & $18 \cdot 4$ \\
June & 29 & 78 & 13,858 & 14,976 & $7 \cdot 0$ & $17 \cdot 4$
\end{tabular}

(Year 2)

July

August

September

October

November

December

January

February

30
24
15
25
30
23
27
23

61
63
68
97
65
68
88
64

$\begin{array}{ll}13,913 & 15,062 \\ 13,978 & 15,160 \\ 13,831 & 14,986 \\ 13,811 & 15,020 \\ 13,840 & 14,982 \\ 13,875 & 14,982 \\ 13,885 & 15,008 \\ 13,981 & 15,300\end{array}$

7.0
$5 \cdot 5$
3.6
5.8
7.2
5.4
6.3
5.9

* People aged 15 years or older who had been registered with the practice for the previous four months and had not received an antidepressant prescription during that period.

significant seasonality for females, whether the period chosen was one year, six months, or four months, and whether or not an adjustment was made for secularo trend.

\section{Discussion}

Analysis of the new prescriptions for antidepressants issued by general practitioners revealed a statistically significant seasonal variation for men only, with peaks in early June and early December. Most repeat prescriptions would have been excluded, since people who had received any antidepressant from their general practitioner during the previous four months were not counted. Nevertheless, it is likely that a few people whose treatment had been started earlier by hospital doctors would have been included.

The prescribing of antidepressants by general practitioners may be expected to reflect the incidence of depression in the community. One advantage of using prescriptions as an indicator is that they can be collected consistently (as with the method used in this study), whereas the special recording of illnesses by busy general practitioners is likely to be subject to bias. It must be remembered, however, that the relation between prescribing and the incidence of depression will not be a simple one. Many depressed people do not receive antidepressants - either because they do 
not visit their doctor, or because their depression is not recognised by the general practitioner, ${ }^{13}$ or because some other treatment is chosen. On the other hand, some patients who are given antidepressants may not in fact be depressed: the distinction between depression and anxiety states is not always clear, ${ }^{14}$ and it can be difficult to distinguish mild depression from distress caused by problems of living.

Our results provide no support for the suggestion by Williams and Dunn ${ }^{9}$ that antidepressant prescribing follows a four-monthly cycle, with troughs in April, August, and December. Williams and Dunn analysed the total numbers of prescriptions dispensed; a substantial proportion of these would have been repeat prescriptions for the same people, so the fluctuations they described cannot be assumed to relate closely to the initiation of treatment for depression. These authors did not present any statistical analyses: when we tested their data using a modification of Edwards' method, ${ }^{15}$ the four-monthly periodicity was found not to be statistically significant $\left(\chi^{2}=5 \cdot 20, \mathrm{df}=2,0.05<\mathrm{P}<0 \cdot 10\right)$.

It is intriguing that the bimodal pattern we found for males, with peaks in early June and early December, was very similar to the variation in general practice consultations for depression described by Harris. ${ }^{8}$ Harris also did not test his data statistically, and application of Edwards' method ${ }^{15}$ again yielded a non-significant result $\left(\chi^{2}=5 \cdot 05, \mathrm{df}=2,0.05<\mathrm{p}<0 \cdot 10\right)$. This would also have been true of our data if, like Harris, we had combined the two sexes. It would be interesting to know whether the seasonality he described was more marked among males.

What could explain a seasonal variation in the prescribing of antidepressants for men but not for women? One possibility is that our results are due to chance, which might account for the seasonality observed in men or for the lack of seasonality in women. If the difference between the sexes is real, it could reflect a different attitude to depression in men. Men might be more reluctant than women to complain of depression to their doctors, doing so only when they have a more clearcut or severe illness. Moreover, general practitioners might also have a higher threshold for diagnosing depression in men or for treating them with antidepressants. Such differences would mean that episodes of depression in men treated by general practitioners would tend to be more serious, bearing a closer resemblance to illnesses requiring admission to hospital. Another possible explanation is that there could be a true sex difference in the seasonality of mild depression. Some studies of suicide suggest that there may be different patterns for the two sexes. ${ }^{2} 16$

If the seasonal pattern suggested by our results and those of Harris were to be confirmed by future studies, it would be important to consider how this pattern related to reports of seasonality in more severe depression. While suicides and hospital admissions for depression are thought to peak in spring and perhaps autumn, ${ }^{1316}$ these two studies suggest that the incidence of depression in the community may peak slightly later-rather than earlier, as might have been expected. It would, of course, be possible that illnesses presenting in June or December would (if treatment by the general practitioner proved to be unsuccessful) lead to admission in the following autumn or spring, respectively.

Our understanding of the relationship between affective disorders and the seasons is still incomplete, but it seems that even mild depression may show some seasonality. Valuable clues about the aetiology of affective disorders could emerge as this seasonal variation is elucidated.

Mrs Beryl Martin and Dr Susan Richards provided valuable assistance. We also thank the general practitioners who participated in this project, and Professor PE Mullen and Professor SD Walter for their advice.

Requests for reprints to: Keren Skegg, Department of Psychological Medicine, University of Otago Medical School, Dunedin, New Zealand.

\section{References}

${ }^{1}$ Kevan SM. Perspectives on season of suicide: a review. Soc Sci Med 1980; 14D: 369-78.

2 Meares R, Mendelsohn FAO, Milgrom-Friedman J. A sex difference in the seasonal variation of suicide rate: a single cycle for men, two cycles for women. Br J Psychiatry 1981; 138: 321-5.

${ }^{3}$ Rosenthal NE, Sack DA, Wehr TA. Seasonal variation in affective disorders. In: Wehr TA, Goodwin FK; eds. Circadian rhythyms in psychiatry. Pacific Grove: Boxwood Press, 1983: 185-201.

${ }^{4}$ Eastwood MR, Stiasny S. Psychiatric disorder, hospital admission, and season. Arch Gen Psychiatry 1978; 35: 769-71.

${ }^{5}$ Parker G, Walter S. Seasonal variation in depressive disorders and suicidal deaths in New South Wales. Br J Psychiatry 1982, 140: 626-32.

${ }^{6}$ Stocks P. Sickness in the population of England and Wales in 1944-1947. Studies on Medical and Population Subjects, No. 2. London: HMSO, 1949.

${ }^{7}$ McCartney JL. Seasonal variation in psychiatric illness. Psychosomatics 1962; 3: 312-6.

${ }^{8}$ Harris CM. Seasonal variations in depression and osteoarthritis. J R Coll Gen Pract 1984; 34: 436-9.

9 Williams P, Dunn G. Cyclical variation in psychotropic drug prescription. J Epidemiol Community Health 1981; 35: 136-8.

${ }^{10}$ Skegg DCG, Doll R. Record linkage for drug monitoring. J Epidemiol Community Health 1981; 35: 25-31. 
${ }^{11}$ Skegg DCG, Doll R, Perry J. Use of medicines in general practice. Br Med J 1977; 1: 1561-3.

12 Walter SD, Elwood JM. A test for seasonality of events with a variable population at risk. $\mathrm{Br} J$ Prev Soc Med 1975; 29: 18-21.

${ }^{13}$ Freeling P, Rao BM, Paykel ES, Sireling LI, Burton RH. Unrecognised depression in general practice. $\mathrm{Br}$ Med $J$ 1985; 290: 1880-3.
14 Johnstone EC, Owens DGC, Frith CD, et al. Neurotic illness and its response to anxiolytic and antidepressant treatment. Psychol Med 1980; 10: 321-8.

${ }^{15}$ Edwards JH. The recognition and estimation of cyclic trends. Ann Hum Genet 1961; 25: 83-6.

16 Näyhä $S$. The bi-seasonal incidence of some suicides. Experience from Finland by marital status, 1961-1976. Acta Psychiatr Scand 1983; 67: 32-42. 